\title{
Treatment of Class II Div 2 Malocclusion using PowerScope: A Cose Report
}

\author{
Dr Luv Agarwal,' Dr Kamlesh Singh, ${ }^{2}$ Dr Ragni Tandon ${ }^{3}$ \\ 'Asst Professor, Dept of Orthodontics, Uttaranchal Dental \& Medical Research Institute, Dehradun, India \\ 3Professor, Dept of Orthodontics, Saraswati Dental College, Lucknow, India
}

\section{ABSTRACT}

Correction of skeletal Class II malocclusion has become a major challenge for orthodontists. Class II jaw discrepancies characterized by mandibular deficiency are treated with fixed functional appliances when there is no active growth present. This case report illustrates the application of PowerScope in 16 years young adolescent male having skeletal Class II Div 2 with mandibular deficiency who was reported with forwardly and irregularly placed upper front teeth with closed bite. The case was treated initially with MBT 0.022" prescription followed by PowerScope. Successful results were obtained with a substantial improvement in facial profile, skeletal jaw relationship and overall aesthetic appearance. PowerScope produced a significant forward movement of mandible which obliterated the need of extractions.

Keywords: Class II Div 2 malocclusion, fixed functional appliance, mandibular deficiency, non-extraction, PowerScope

\section{INTRODUCTION}

Class II malocclusion poses a major challenge in terms of treatment planning and successful management. Class II malocclusion may or may not involve skeletal discrepancy. The mandible may be normal or retruded with respect to maxilla, or maxilla could be protrusive with respect to mandible. Skeletal Class II malocclusion can be due to maxillary prognathism, mandibular retrognathism or a combination of both. Retrusion of mandible is the most common feature of class II malocclusion rather than maxillary prognathism, as outlined by McNamara. It may be due to various etiological factors such as small sized mandible, posterior placement of condyle in glenoid fossa or functional mandibular shift. In growing cases, mandibular advancement is achieved using functional appliance that employs growth modulation techniques. Severity of jaw base discrepancy, patient compliance and the amount and timing of growth spurts play crucial. Growth spurts are during 10-13 years in girls and 11-14 years for boys. ${ }^{1-3}$ Attention is given on pubertal growth spurt in adolescents as growth modification tools are preferred in Class II malocclusion. Functional appliance acts by redirecting or impeding the maxillary growth with simultaneous stimulation of mandibular growth. Removable functional appliances such as activator, bionator, Twin block and Frankel regulator is advocated in patients where active growth is present. Fixed functional appliances such as Herbst, Jasper jumper, Universal bite jumper and Forsus are applicable in non-compliant patients who have crossed the adolescent growth spurt. ${ }^{4.5}$ The mandibular advancement induced by these appliances cause changes in molar relation, overjet correction and increase in mandibular length. ${ }^{6-8}$

Powerscope is the latest innovation among fixed functional appliances developed by Dr. Andy Hayes. It applies continuous force and produces favourable dentoalveolar effects such as restraining maxillary growth, stimulation of mandibular growth, distal maxillary movement and mesial positioning of mandibular arch. Proclined upper incisors are intruded to unlock the distally positioned mandible, thereby advance the path of closure of mandible. This appliance does not require patient's compliance and can be used in conjugation with orthodontic brackets. 9,10

This paper presents a non-extraction approach for the treatment of skeletal Class II Div 2 malocclusion with mandibular deficiency and impinging overbite using PowerScope.

\section{CASE REPORT}

A 16-year-old male patient presented with a chief complaint of irregularly placed upper anterior teeth and distally positioned mandible. The clinical examination showed Angle's Class II Div 2 malocclusion, $100 \%$ overbite, $0 \mathrm{~mm}$ overjet, retroclined upper central incisors and labioversion of upper lateral incisors. Cephalometric analysis showed Class II skeletal pattern with ANB angle 40, horizontally directed growth, retrusive mandible and skeletal deep bite. The maxillary 

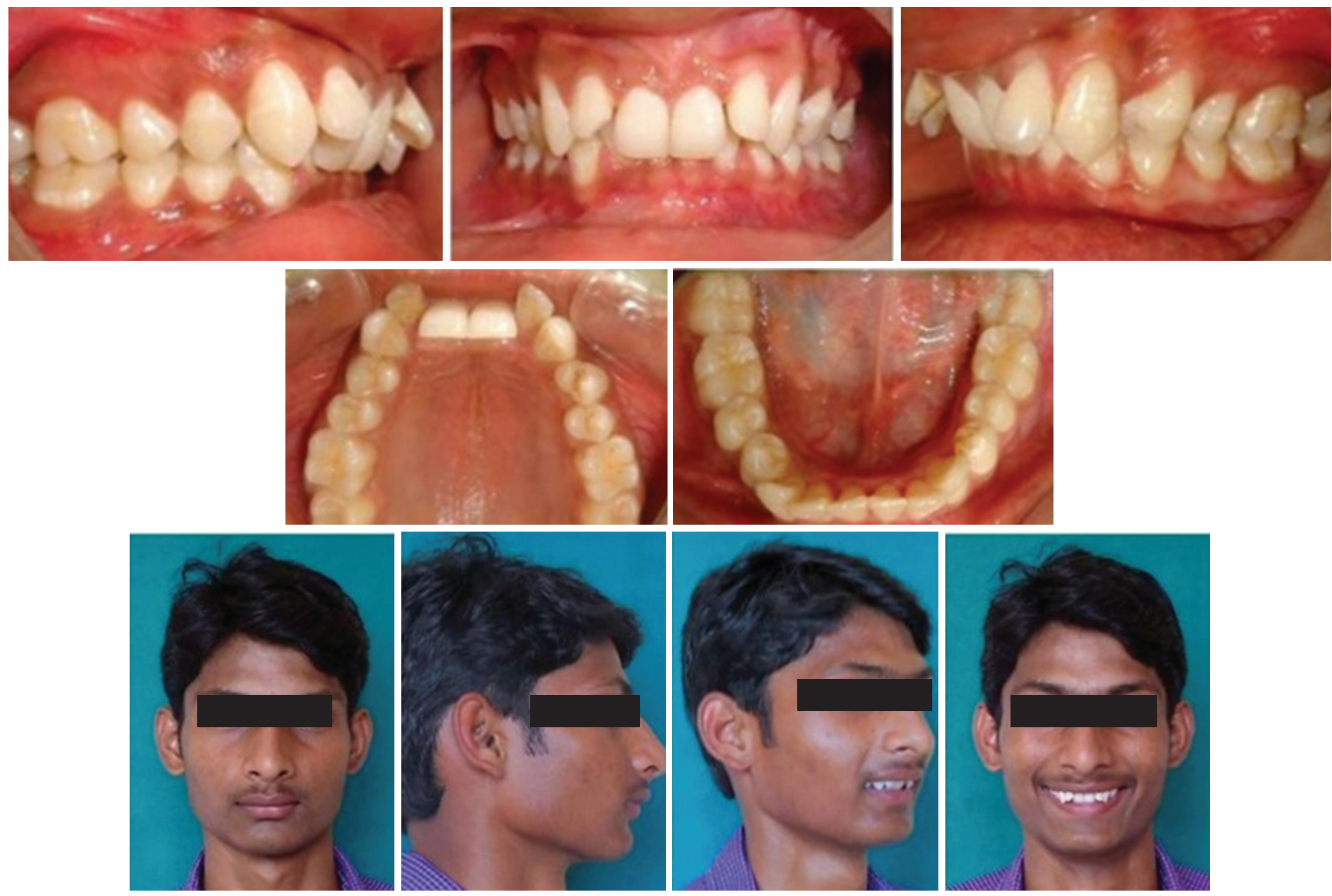

Figure 1: Pre-treatment intra-oral and extra-oral photographs

and mandibular arch form exhibited squarish shape with severe curve of spee in mandibular dentition. Intraoral examination showed Class II end-on molar relation on both sides and Class II canine relation on both sides; scissor bite was present with respect to 24. Upper and lower dental midline were coincident (Figure 1).

Extra-oral examination displayed reduced lower facial height, competent lips and convex profile with the presence of passive lip seal and posteriorly divergent and retrusive mandible. Distinct concavities were seen in the inferior border of C2, C3 and C4 in cervical vertebrae which corresponds to SMI 7 indicating deceleration stage which signifies $10 \%$ to $25 \%$ adolescent growth left. The panoramic radiograph showed the presence of all permanent teeth (Figure 2).
Treatment objective: To improve facial profile, achieve adequate overjet and overbite relations, improve smile esthetics, and to obtain Class I canine and molar relation without extracting teeth. Levelling of curve of spee is required in mandibular arch with the maintainence of inter-canine and inter-premolar widths.

Treatment plan: A non-extraction approach was undertaken. MBT 0.022" brackets was selected and fixed functional appliance PowerScope was used at a later stage to address skeletal problem thus utilizing the remaining growth (Figure 3).

Treatment progress: The archwire sequence was coaxial, 0.014 Niti, 0.016 Niti, 16×22 Niti, 16×22 Ss; each

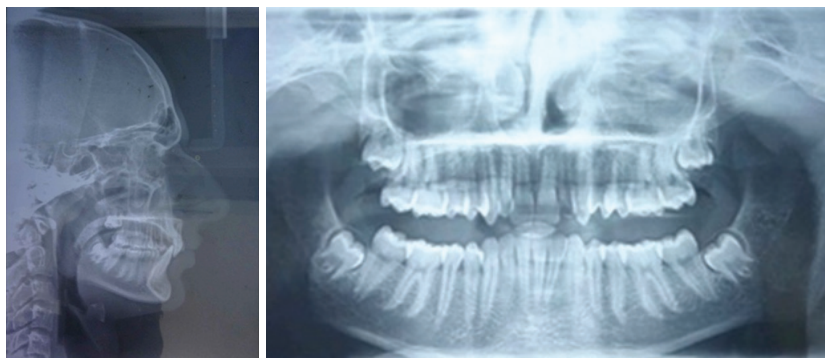

Figure 2: Pre-treatment lateral cephalogram and OPG 

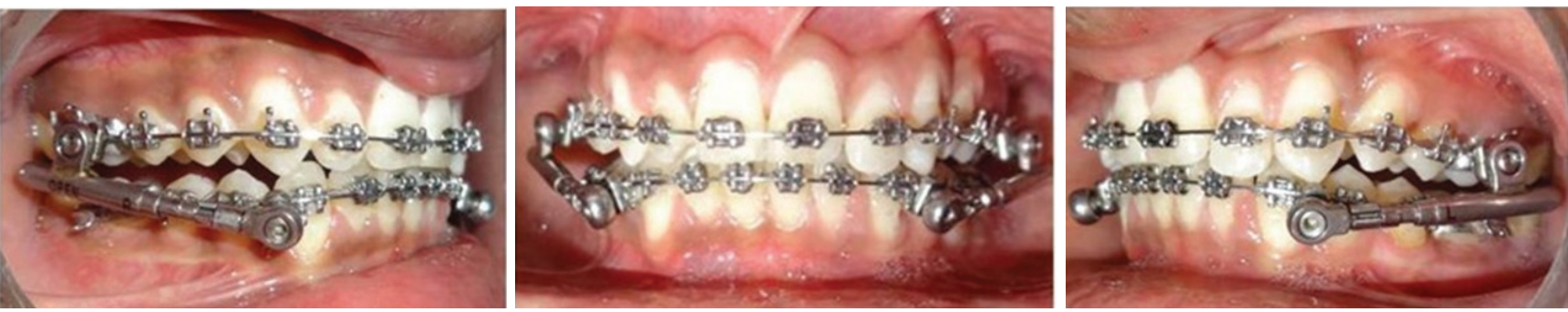

Figure 3: PowerScope installation

wire was placed for a period of 1 month. Levelling and alignment was completed in 10 months time, then $17 \times 25$ SS was placed to stabilize the arch. This was followed by mandibular advancement using PowerScope. A 100 lingual crown torque was applied in lower anterior teeth to prevent flaring of mandibular incisors. Then, a Class II corrector was placed on both sides to advance the mandible forward and to correct the end-on molar relation. There was a substantial improvement in patient's profile due to mandibular advancement and soft tissue modifications.

The PowerScope was employed for a period of seven months and following its removal, Class II vertical elastics $(5 / 16,4 \mathrm{oz})$ was used to achieve interdigitation and to support achieved sagittal correction. Final stage OPG, lateral cephalograms and photographs were taken (Figure 4, 6). Pre-treatment and posttreatment cephalometric readings were compared and superimpositions were made (Figure 5). The total treatment time was 17 months; then after upper and lower lingual retainers were given.

\section{Treatment results:}

- Improved facial profile

- Increased mandibular length

- Proclination of upper and lower incisors

- Class I molar and canine relation achieved on both sides

- Decrease in lower anterior facial height

- Improved facial balance and smile esthetics.
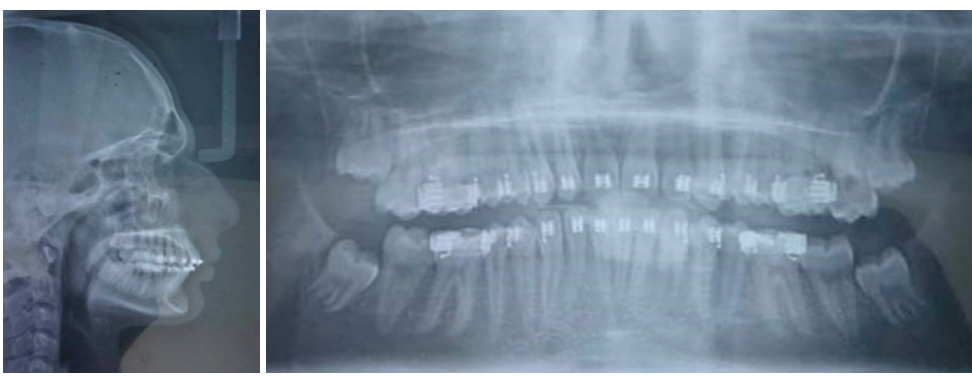

Figure 4: Final stage Lateral cephalogram and OPG (before debonding)

\section{DISCUSSION}

Fixed functional appliance works by restriction of forward growth of maxilla and it promotes distal movement of maxillary molars and mesial movement of mandibular molars. Other effects are retroclination of maxillary incisors and proclination of mandibular incisors. ${ }^{11,12}$

The PowerScope is a fixed one piece appliance available in one size and suits all Class II cases. One piece concept prevents dislodgement of appliance on jaw movements. The appliance allows quick and easy wire-to-wire installation and prevents bond failure of bracket and buccal tube and it is customized with crimpable shims supplied among the PowerScope armamentarium. The appliance has ball and socket joint at two ends which allows excellent jaw movements reducing patient discomfort. 13,14

Mandibular incisor proclination is the most common dentoalveolar side effect seen with PowerScope which can be prevented by cinch back of archwire, figure of ' 8 ' consolidation of mandibular arch and lingual crown torque in anterior segment of the mandibular arch.

On comparing the cephalometric outcomes, considerable improvement in skeletal, dental and soft tissue parameters were observed at the end of PowerScope treatment. There was 50 reduction in ANB angle from 9 to 40 posttreatment and there was increase in mandibular length by

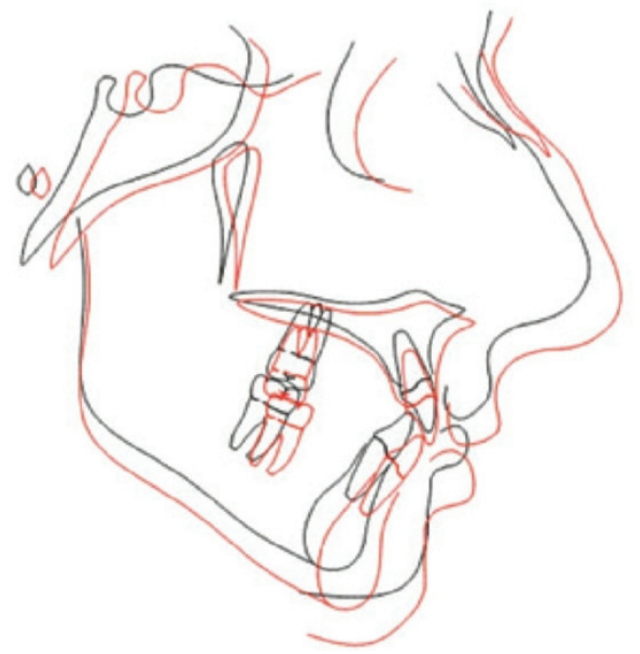

Figure 5: Cephalometric superimpositions 

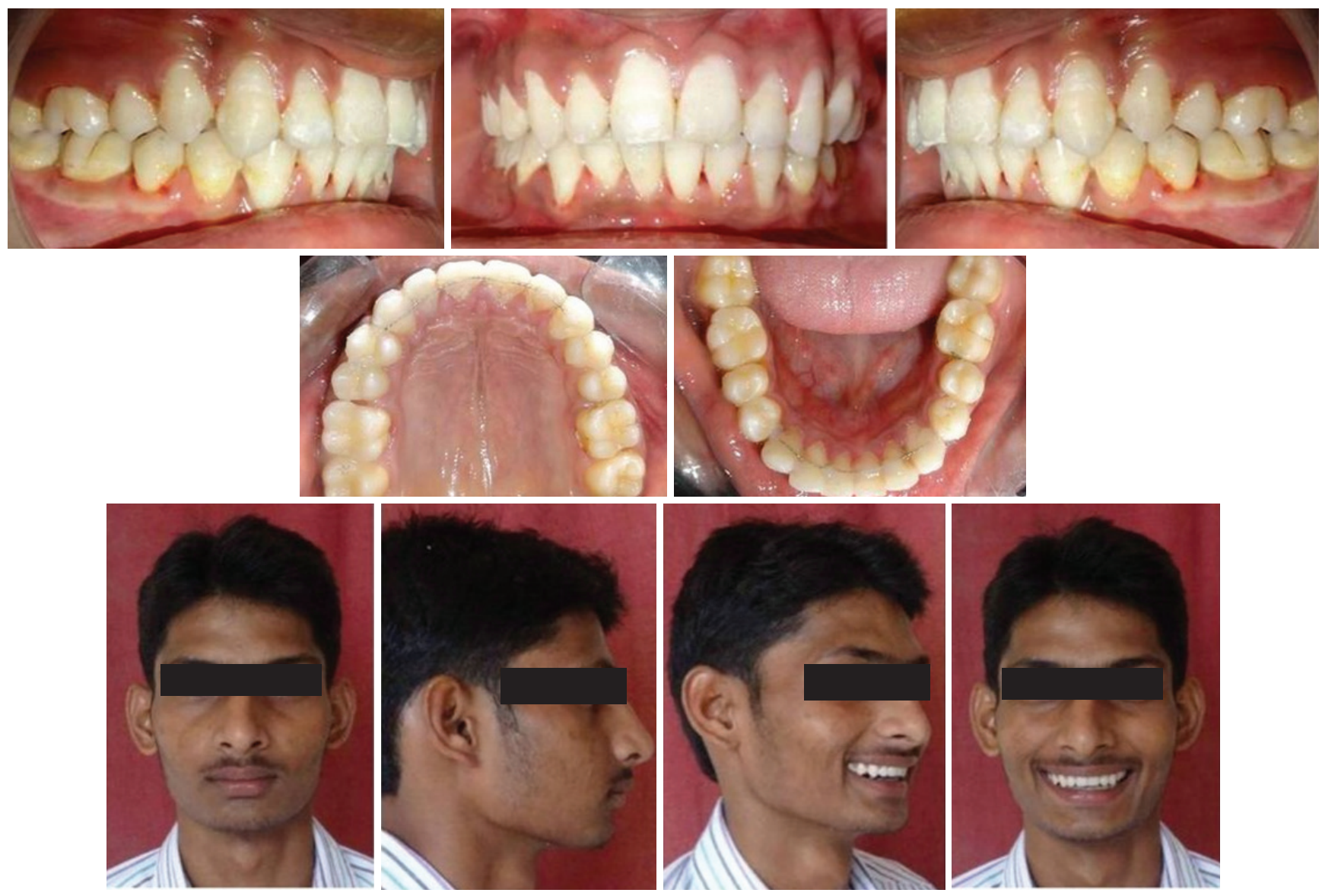

Figure 6: Post-treatment intra-oral and extra-oral photographs

$4 \mathrm{~mm}$ (70-74 mm). Maxillary length remained unchanged after Powerscope correction. Substantial improvement in soft tissue and skeletal profile was observed with a tendency towards orthognathic profile. Esthetic line changed from $-2 \mathrm{~mm}$ to $-3.5 \mathrm{~mm}$ in upper lip and $-4.5 \mathrm{~mm}$ to $-2 \mathrm{~mm}$ in lower lip. Pre-treatment and post-treatment cephalometric findings were compared (Table 1).

The PowerScope has certain advantages over Class II elastics. The compressed Niti spring provides push force mesial to maxillary molars and distal to mandibular canine, and force is mainly horizontal and slight intrusive in nature whereas Class II elastics delivers pull type of force and force is both extrusive and horizontal in force vector. ${ }^{8}$

Rectangular stainless steel arch wire of 0.025 " in horizontal dimension is required to use the appliance. It provides precise fit for direct-to-wire attachments and restricts the appliance from unwanted movement and prevents soft tissue irritation. ${ }^{15,16}$

PowerScope itself does not cause forward repositioning of the mandible in anterior direction and when patient functions in a maximum intercuspation position, its internal spring works. Therefore, a significant midline discrepancy can still be seen. 
Table 1: Comparison of cephalometric findings

\begin{tabular}{|c|c|c|c|c|}
\hline \multicolumn{2}{|c|}{ Parameter } & Pre-treatment & Post-treatment & Difference \\
\hline \multicolumn{2}{|l|}{ SNA } & 84 & 83 & -1 \\
\hline \multicolumn{2}{|l|}{ SNB } & 75 & 79 & 4 \\
\hline \multicolumn{2}{|l|}{ ANB } & 9 & 4 & -5 \\
\hline \multicolumn{2}{|c|}{ Wits appraisal } & $6.5 \mathrm{~mm}$ & $3.5 \mathrm{~mm}$ & $-3 \mathrm{~mm}$ \\
\hline \multicolumn{2}{|c|}{ Maxillary length } & $53 \mathrm{~mm}$ & $53 \mathrm{~mm}$ & 0 \\
\hline \multicolumn{2}{|c|}{ Mandibular length } & $70 \mathrm{~mm}$ & $74 \mathrm{~mm}$ & $4 \mathrm{~mm}$ \\
\hline \multicolumn{2}{|c|}{ Ramus length } & $50 \mathrm{~mm}$ & $50 \mathrm{~mm}$ & 0 \\
\hline \multirow{2}{*}{ S Line } & Upper & $2 \mathrm{~mm}$ & $0 \mathrm{~mm}$ & $-2 m m$ \\
\hline & Lower & $1 \mathrm{~mm}$ & $0 \mathrm{~mm}$ & $-1 \mathrm{~mm}$ \\
\hline \multirow{2}{*}{ E- Line } & Upper & $-2 \mathrm{~mm}$ & $-3.5 \mathrm{~mm}$ & $1.5 \mathrm{~mm}$ \\
\hline & Lower & $-4.5 \mathrm{~mm}$ & $-2 \mathrm{~mm}$ & $-2.5 \mathrm{~mm}$ \\
\hline \multicolumn{2}{|c|}{ 1-1(degree) } & 124 & 133 & 9 \\
\hline \multicolumn{2}{|c|}{ 1-SN(degree) } & 116 & 105 & -11 \\
\hline \multicolumn{2}{|c|}{ Go-Gn-SN(degree) } & 29 & 33 & 4 \\
\hline \multicolumn{2}{|l|}{ FMA } & 24 & 28 & 4 \\
\hline \multicolumn{2}{|l|}{ IMPA } & 97 & 103 & 6 \\
\hline \multicolumn{2}{|l|}{ Y-axis } & 60 & 63 & 3 \\
\hline
\end{tabular}

\section{REFERENCES}

1. Proffit WR. Malocclusion and dentofacial deformity in contemporary society. Contemporary Orthodontics. 4th ed. St. Louis: Mosby Elsevier; 2007. p.3-23.

2. Uribe, F, Nanda R. Treatment of Class II, Division 2 malocclusion in adults: Biomechanical considerations, J Clin Orthod. 2003;37:599-606.

3. MCNamara JA Jr. Components of class II malocclusion in children 8-10 years of age. Angle Orthod. 1981;51:177-202.

4. Tulloch JFC, Proffit WR, Phillips C. Influences on the outcome of early treatment for Class II malocclusion. Am J Orthod. $1997 ; 111: 533-42$.

5. Jakobson SO. Cephalometric evaluation of treatment effect on Class II Division 1 malocclusions. Am J Orthod. 1967;53:446-56.

6. Weiland FJ, Droschi H. Treatment of Class II Div 1 malocclusion with the Jasper Jumper. A case report. Am J Orthod Dentofac Orthop. 1996;109:1-9.

7. Graber TM, Rakosi T, Petrovic A. Dentofacial Orthopedics with Functional Appliances. St. Louis: CV. Mosby Co.; 1997;p.346-52.

8. Ritto AK, Ferreira AP. Fixed functional appliances: A classification. Funct Orthod. 2000;17:12-30, 32.

9. Cozza P, Baccetti T, Franchi L, De Toffol L, McNamara JA Jr. Mandibular changes produced by functional appliances in class II malocclusion: A systematic review. Am J Orthod Dentofacial Orthop 2006;129:599.e1-12.

10. Papadopoulos MA. Orthodontic treatment of the Class II noncompliant patient.

11. Vogt W. The Forsus fatigue resistant device. J Clin Orthod. 2006;40:368-77.

12. Cetlin NM, Ten Hoeve A. Nonextraction treatment. J Clin Orthod 1983;17:396-413.

13. Pancherz H, Ruf S, Kohlhas P. "Effective condylar growth" and chin position changes in Herbst treatment: A cephalometric roentgenographic long-term study. Am J Orthod Dentofac Orthop. 1998;1 14:437-46.

14. Nelson B, Hansen K, Hägg U. Class II correction in patients treated with class II elastics and with fixed functional appliances: A comparative study. Am J Orthod Dentofacial Orthop 2000;1 18:142-9.

15. Heinig N, Göz G. Clinical application and effects of the Forsus spring. A study of a new Herbst hybrid. J Orofac Orthop 2001;62:436-50.

16. Khumanthem S, Kumar M, Ansari A, Jain A. Correction of Class II using Powerscope Appliance - A case report. Arch of Dent and Med Res. $2016 ; 2(3): 120-5$ 